\title{
Cancer and Aging; Preparing for Silver Tsunami
}

\author{
Keywords: Older cancer survivors; Comprehensive Geriatric \\ Assessment
}

\begin{abstract}
Growing number of older adults is one the most significant sociodemographic changes in the United States in the next few decades. Advancing age is associated with increased incidence of cancer and other age-related health conditions. It is common that older cancer patients have concurrent conditions and comorbidities that may affect treatment decisions, prognosis and overall survival. Assessment and care for older cancer patient is more complex than caring for younger patient. Comprehensive Geriatric Assessment (CGA) is a useful method for assessing older patients with cancer. CGA is a multidisciplinary evaluation designed to assess and manage elderly patient's medical, psychosocial, and functional capabilities. In this paper we will review domains of CGA and their impact on older cancerpatient's outcome.
\end{abstract}

\section{Abbreviations}

CGA: Comprehensive Geriatric Assessment; ECOG-PS: Eastern Cooperative Oncology Group Performance Status; KPS: Karnofsky Performance Status; ADL: Activities of Daily Living; iADL: instrumental Activities of Daily Living; OARS: Older Americans Resources and Services; VES-13: Vulnerable Elders Survey-13; MNA: Mini Nutritional Assessment; CRT: Chemo Radiation Therapy; MMSE: Mini Mental Status Examination; MoCA: Montreal Cognitive Assessment; CDT: Clock-Drawing Test; CRCI: Chemotherapy-Related Cognitive Impairment; MOS-SSS: Medical Outcome Study-Social Support Survey; MSPSS: Multidimensional Scale of Perceived Social Support; PIM: Potentially Inappropriate Medications; GDS: Geriatric Depression Scale; HADS: Hospital Anxiety and Depression Scale

\section{Introduction}

Cancer is the second leading cause of death in the United States. It is estimated that $1,665,540$ new cases of invasive cancer were diagnosed in 2014 and about 585,720 deaths occurred [1]. Moreover, as of January 2012, there were approximately 13.7 million cancer survivors in the United States with prevalence projected to approach 18 million by 2022 [2]. Currently, more than $60 \%$ of newly diagnosed cancers and $70 \%$ of cancer related deaths occurring in patients over 65 years [3]. In 2015, over 47 million Americans are older than 65 years of age which is expected to increase to 65 million by 2025 [4]. As a result, the incidence of cancer in aging population is expected to increase significantly.

Older patients have unique characteristics that separate them from younger patients. With increasing age physiologic reserve decreases in the human body (Figure 1), however the rate of this decline varies between individuals [5]. At the same time, changes in functional capacity, cognition and comorbidities that accompany advanced age may influence different aspects of elderly patient's life such as life expectancy, or risk of hospitalizations [6,7]. As definition by the American Medical Association, frail patients are the group of patients that present the most complex and challenging problems to

\section{Journal of}

Geriatrics and Palliative Care

\author{
Sanam Mahmoudzadeh and Armin Shahrokni* \\ Memorial Sloan Kettering Cancer Center, Geriatrics Service, 1275 \\ York Avenue, New York, USA

\section{*Address for Correspondence} \\ Armin Shahrokni, MD, Memorial Sloan Kettering Cancer Center, \\ Geriatrics Service, 1275, York Avenue, New York, USA, Tel: +1-646- \\ 888-3250; Fax: +1-646-888-3181; E-mail: shahroka@mskcc.org \\ Submission: 14 July 2015 \\ Accepted: 21 August 2015 \\ Published: 31 August 2015 \\ Copyright: ๑ 2015 Mahmoudzadeh S, et al. This is an open access \\ article distributed under the Creative Commons Attribution License, \\ which permits unrestricted use, distribution, and reproduction in any \\ medium, provided the original work is properly cited.
}

the physician and all health care professionals, and these patients have tendency to develop adverse outcomes [8]. The overall age related changes can largely impact the tolerance to cancer treatment and shift risk-benefit ratios of such treatments in this growing population [9].

In this manuscript, we will discuss the unique characteristics of older patients, methods of assessing them, and their relationship to older cancer patients' outcome.

\section{Comprehensive Geriatric Assessment}

Older patients, with or without cancer, have certain characteristics that may not be detected during routine medical history and physical exam [10]. Comprehensive Geriatric Assessment (CGA) includes a multidisciplinary evaluation of an older adult geared towards assessing complex problems of older persons which frequently go unrecognized. Moreover, the need for services is assessed and a coordinated plan for the interventions focusing on the elderly problems is developed. CGA evaluates multiple domains including functional status, comorbidities, cognition, nutritional status, social support, psychological state and medication list (Table 1) [11].

\section{Performance status}

While in general, performance status of cancer patients are measured by either Eastern Cooperative Oncology Group Performance Status (ECOG-PS) [12] or Karnofsky Performance Status (KPS) [13], older cancer patients require more comprehensive assessment of their functional status.

Activities of Daily Living (ADL) and instrumental Activities of Daily Living (iADL): The assessment of functional status of older cancer patients should include assessment of their daily activities [14] and instrumental activities of daily living [15]. Validated questionnaires are available for proper assessment of these activities. Katz Activity of Daily Living assesses patients' independency in bathing, dressing, toileting, transferring, continence, and feeding. For each completely independent activity, patients receive a score of 1 , and for somewhat or completely dependent activities, patients receive a score of zero. Instrumental activities of daily 


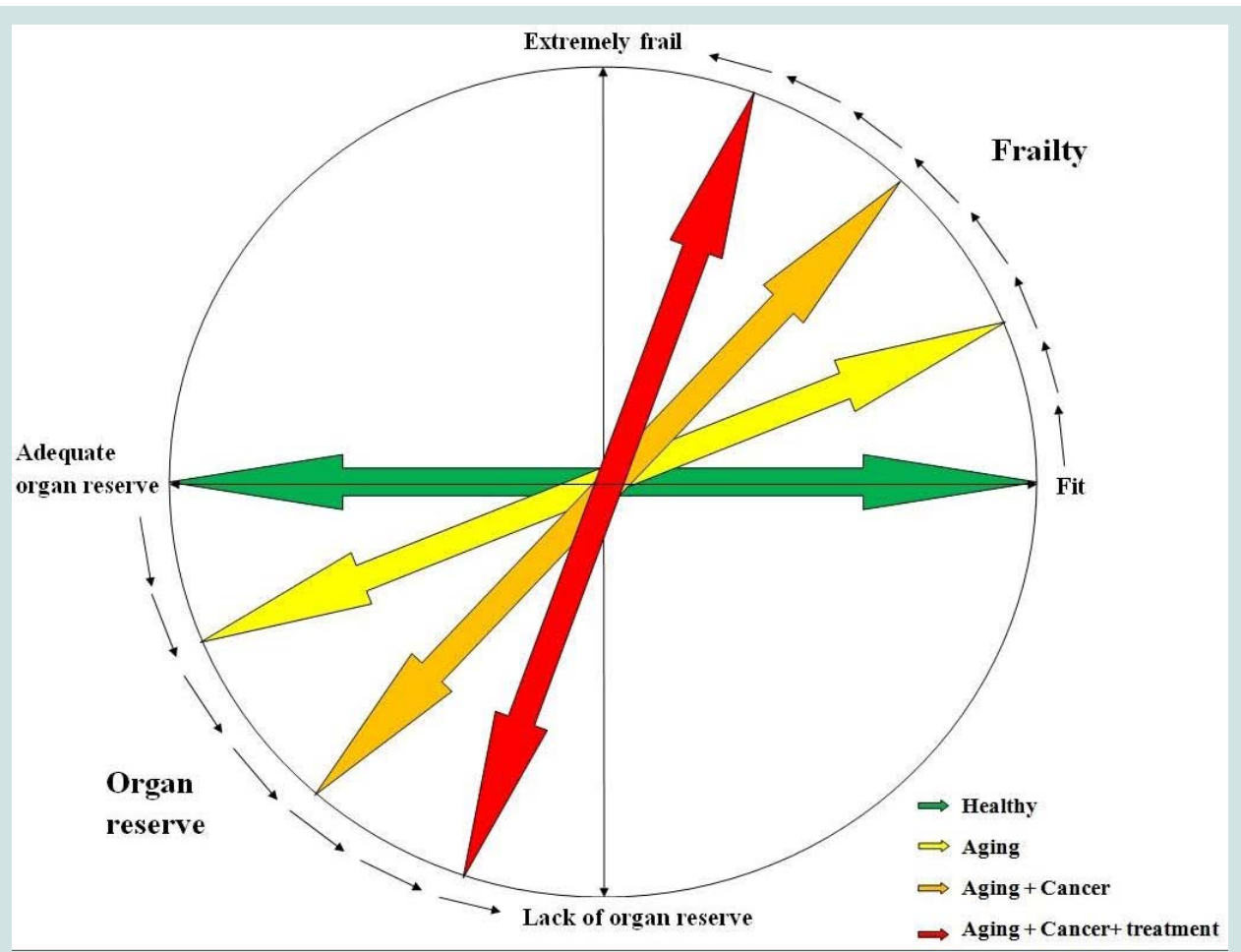

Figure 1: Impact of aging, cancer, and cancer treatment on patients' fitness and frailty.

living are usually measured by Lawton questionnaire [16]. For each instrumental activity of daily living (use of telephone, shopping, meal preparation, housekeeping, laundry, mode of transportation, taking medication and ability to handle finances), patients are asked to rate their level of independency (or dependency). The score ranges from 8 (completely independent in all activities) to zero (completely dependent in all activities). A shorter, more practical method of assessing instrumental activities of daily living could be performed by administering the section of instrumental activities of daily living of Older Americans Resources and Services Program (OARS) [17]. Other questionnaires that can be used in this setting include The Vulnerable Elders Survey-13 (VES-13) [18] which takes into account age (75-84 vs. $=>85)$, general overall health status, having difficulty with certain physical activities that includes some of the activities of daily living (e.g. bathing), and instrumental activities of daily living (e.g. shopping).

These measurements of older cancer patients' performance

Table 1: Components of comprehensive geriatric assessment.

Components of Comprehensive Geriatric Assessment

Activities of Daily Living (ADL)

Instrumental Activities of Daily Living (iADL)

\section{Cognition}

Social Support

Polypharmacy

Nutrition

Combrid condtions

Emotional distress, Depression status have shown to be associated with the outcome of patients. In the hallmark study by Dr. Hurria and colleagues, 500 patients age 65 or older with solid tumors underwent a comprehensive geriatric assessment prior to the initiation of their chemotherapy [19]. They were followed prospectively for the development of chemotherapy toxicity (categorized as grade 3 or more toxicity). In the bivariate analysis, hearing impairment, having one or more falls in the 6 months prior to the start of chemotherapy, being limited in walking one block, and needing assistance with medications were associated with chemotherapy toxicity. In another study, conducted by Dr. Extermann and colleagues, 562 patients older than age 70 were recruited at the start of chemotherapy [20]. The variable of interest was development of hematological toxicity grade 4 or grade 3 or 4 nonhematological toxicities. Similar to Dr. Hurria's study, all patients had comprehensive geriatric assessment before starting chemotherapy. In the final model, iADL dependency remained strongly predictive of toxicity even after adjustment for ECOG-PS. The independency of other methods of measuring performance status (e.g. ADL or iADL) from ECOG-PS was of no surprise. Previously, an Italian study [21] performed comprehensive geriatric assessment in 363 older cancer patients (median age of 72 years) with solid and liquid tumors. Of the patients with good performance status, $9.3 \%$ and $37.7 \%$ had ADL or iADL limitations, respectively.

Importance of assessing functional status of older cancer patients by methods described above has also been shown in studies of cancer patients undergoing surgery [22]. In one study [23], 182 colorectal cancer patients with median age of 80 had comprehensive geriatric assessment preoperatively. Those with iADL dependency were approximately 4 times more likely to develop any surgical 
complication.

Comprehensive assessment of patients' functional status can be useful in decision making. In a study on 328 breast cancer patients older than age 70, ADL and iADL dependency were associated with greater likelihood of mortality within 3 years of diagnosis [24]. Another study performed geriatric assessment on 460 older cancer patients aged $\geq 70$ years undergoing surgery. iADL dependency was associated with a $50 \%$ increase in post-operative complications. Again, in the multivariate analysis, after adjusting for performance status, iADL was still associated with post-surgical complications [25].

Assessment of prior history of falls: is an important part of the functional status assessment of older patients with cancer. Falling is common among older patients regardless of their cancer status. Most of the falls are related with one or more identifiable risk factors (e.g. unsteady gait, weakness) leading to considerable morbidity and mortality among elderly people [26,27]. In a study [28] on 421 cancer patients (median age of 60 years) with chemotherapy induced peripheral neuropathy, $11.9 \%$ and $26.6 \%$ reported a recent fall and functional impairment, respectively. The rate of fall-related injuries among those receiving two neurotoxic chemotherapy agents was higher compared to those receiving one or no neurotoxic agents (9.15 vs. 7.76 vs. 5.19 per 1000 person-months, respectively) [29]. Those with a history of falls in the 6 months prior to the start of chemotherapy were more likely to develop chemotherapy toxicity [30]. Many older patients use assisted devices such as a cane or walker for ambulation, and therefore special attention should be paid to the use of such devices, if a neurotoxic chemotherapy agent is to be administered. Moreover, maintaining balance requires coordination between multiple senses. Older patients may have vision or hearing impairment, and therefore it is vital to assess for such impairment and refer to specialists for proper eyewear or hearing aids.

\section{Nutrition status}

Worldwide, the prevalence of malnutrition in cancer survivors ranges from 24 to $80 \%$. Malnutrition adversely affects the clinical outcomes in cancer patients including length of hospital stay, chemotherapy tolerance, quality of life and overall survival [31]. Weight loss alone or in combination with other laboratory parameters (e.g. Albumin) is considered the main indicator of poor nutritional status [32]. Mini Nutritional Assessment (MNA) is the tool for evaluating the risk of malnutrition in elderly people. This assessment categorizes the patients as normal (adequate nutrition), borderline (at risk of malnutrition), or under nutrition based on anthropometric measurements, global assessment, dietary questionnaire, and a subjective assessment [33]. In a prospective study on 207 patients with median age of 52.31 years undergoing radiotherapy for different cancer types, malnutrition was present at $31 \%$ of them at start of treatment, which increased to $43 \%$ at the end of radiotherapy and decreased to $8 \%$ after 6 months follow up with nutritional support [34]. In a prospective study of head and neck cancer patients who underwent surgery, patients who received higher amount of nutritional support had decreased length of hospital stay and fistula wound complications compared to the other group [35]. In another study on 182 colorectal cancer patients with a median age of 80 , impaired nutrition was a predictor of early mortality (HR
2.39, 95\% CI 1.24 to 4.61) [23]. Malnutrition is frequently seen in patients with esophageal cancer due to anorexia and dysphagia before starting treatment [36]. A French study on 105 esophageal cancer patients with median age of 63.6 who underwent definitive chemo radiation therapy (CRT) treatment (external radiotherapy delivered concomitantly with cisplatin-based chemotherapy) showed that non-responding and responding patients to CRT were significantly different on baseline nutritional parameters including weight loss (10\% vs $5.8 \%,(\mathrm{P}=.0047))$, serum albumin level $(35 \mathrm{~g} / \mathrm{L}$ vs $38.7 \mathrm{~g} / \mathrm{L}$, $(\mathrm{P}=.0004))$ and Body Mass Index $(22.8 \mathrm{~kg} / \mathrm{m} 2$ vs $25.2 \mathrm{~kg} / \mathrm{m} 2, \mathrm{P}=$ 0.01 ) [37]. Considering this data, nutritional interventions may play an important role in esophageal cancer treatment.

\section{Cognition status}

Cognitive impairment is highly prevalent in cancer patients and can lead to significant impairment in their ability to function and to tolerate the treatment [38]. A cognitive assessment is an essential part of CGA. Folstein Mini Mental Status Examination (MMSE) has been extensively validated and easy to use [39]. It is an 11-question test that evaluates different areas of cognitive function including: orientation, registration, attention and calculation, recall, and language [40]. MMSE results are categorized as normal (27-30), intermediate (2426 ), or indicative of cognitive dysfunction $(<24)$. In order to screen patients for mild cognitive impairment, but with a normal MMSE score, investigators have used the Montreal Cognitive Assessment (MoCA) [41]. The MoCA assesses various cognitive domains including memory, visuospatial abilities, executive functions, attention and concentration, orientation, conceptual thinking, calculation and language. Administration time is approximately 10 minutes with a possible maximum score of 30 points (Normal: $\geq 26$ points) [41]. The Mini-Cog test is another method of cognitive assessment composed of a 3 -item recall test with 1 point for each recalled word and a Clock-Drawing Test (CDT) with 0 point for an abnormal CDT and 2 points for a normal one. The lower the score on the Mini-Cog, the greater the severity of the cognitive impairment [42]. Cognitive impairment is associated with increased use of health services and a higher mortality rate. In a prospective study of 3954 patients older than 60 years (mean age of 68 years), subjects with moderate to severe cognitive impairment were more likely than those with no impairment to be hospitalized (29.1\% and $16.5 \%)$, to visit the emergency department $(55.8 \%$ and $38.5 \%)$ and to have greater mortality ( $8.2 \%$ and $2.8 \%$ ) [43]. Pre-operative cognition impairment is a well-known risk factor for post-operative delirium. In the study of 182 colorectal cancer patients (median age of 80 ), subjects with MMSE scores < 24 had a significantly higher rate of delirium [23]. In another study on 144 elderly patients undergoing major surgery, $44 \%$ of them developed postoperative delirium. In the multivariable analysis, pre-existing dementia was the strongest risk factor for the development of postsurgical delirium [38]. Complaints of impaired cognition following chemotherapy are fairly common among cancer survivors (chemotherapy-related cognitive impairment (CRCI) [44]. A study of breast cancer patients showed that in patients treated with high-dose chemotherapy the risk of cognitive impairment was 3.5-times higher compared to patients who received standard-dose chemotherapy (95\% CI $=1.0-12.8)$ [45]. It has been shown that cognitive decline can take place in about half of prostate cancer 
patients on androgen deprivation therapy $[46,47]$.

\section{Social support}

Older patients rely on their family and friends in the course of cancer treatment for care and support [48]. As patients get older, their social support and network of friends and families diminishes. Studies have shown that patients with more social support and a larger social network tend to be healthier, happier, and less at risk of developing adverse outcomes [49-51]. Social support can be measured by a variety of methods. At minimum, the healthcare provider should ascertain the patient's living condition and marital status, as those who live alone or are widowed, divorced, or never married could be at higher risk for adverse healthcare outcomes [52].

Additionally, healthcare providers should identify the primary caregiver among all potential caregivers (spouse, children, first or second degree relatives), and assess his/her capability of taking care of their older patient with cancer. Caregivers provide significant care for older cancer patients with almost no cost to the healthcare system. Empowering caregivers through face to face or group education on how to approach and manage older cancer patients' symptoms may lead to healthcare cost saving by avoiding hospitalization or emergency room visits. Validated questionnaires are available to further assess social support of cancer patients. Two of the most commonly used social support questionnaires are the Medical Outcome Study- Social Support Survey (MOS-SSS) and the Multidimensional Scale of Perceived Social Support (MSPSS) [53]. MOS-SSS is a 19-item questionnaire that assesses patients' social support in four domains: emotional/informational support, tangible support, affectionate support, positive social interaction and one additional item asking patients how frequently they have someone to do things with to help relieve their anxiety. Patients are asked to state the availability of social support for each domain on a 5-point Likert scale. Another study showed that MOS-SSS 12-item and 4-item are also psychometrically sound and can be used for both research and clinical practices. MSPSS is a 12-item questionnaire that asks patients to answer their level of agreement with each statement on a 7-point Likert scale [54]. MSPSS then categorizes the responses from the patients into perceived support from significant other, family and friends.

\section{Poly-pharmacy}

As patients age, they develop more comorbid conditions that need to be managed by multiple medications. Although there is no consensus on the definition of polypharmacy [55], many scholars have referred to polypharmacy as greater than 5 medications [56], or excessive use of medications. Some authors, defined polypharmacy as use of 6-9 medications, and 10 or more medications was considered as excessive polypharmacy [57]. Others have focused on prescribed potentially inappropriate medications (PIM) [58] rather than the number of prescribed medications. For many years, the American Geriatrics Society has published the Beers list which includes potentially inappropriate medications for older patients. Polypharmacy, defined by any method, has potential adverse consequences on patients' overall outcome. Patients with polypharmacy are at higher risk for developing drug-drug interaction, noncompliance with the medication, increased costs, and unnecessary duplication of therapy [59]. While polypharmacy is a common problem among older patients with cancer [60,61], few studies conducted in older cancer patients have failed to show the impact of polypharmacy on this population. In one study [62], 500 older patients (mean age of 73 years) with solid tumors undergoing chemotherapy were followed prospectively. Although the rate of PIM and excessive medication use was high, neither of these factors was associated with chemotherapy toxicity, or hospitalization. Regardless, it is critical for cancer care provider to assess older cancer patients' list of medication, and pay special attention to drug-drug interaction in order to avoid increase in drug toxicity or decrease in chemotherapy efficacy.

\section{Comorbid conditions}

As patients [63] age, they may develop more comorbid conditions. Patients with more comorbid conditions tend to visit specialist more often compared to those with fewer comorbidities [64]. The cost of managing patients with multiple comorbid conditions is more than those with less comorbidities [65]. Older cancer survivors with multiple comorbid conditions are at higher risk for adverse outcomes. In a study of 455 older (age $>60$ ) rectal cancer patients, authors found out that those with more comorbid conditions were at higher risk for poorer overall survival $(\mathrm{HR}=1.7, \mathrm{P}=0.03)$ [66]. The number of comorbid conditions may also affect cancer treatment decision making. In a study [67] of elderly candidates for radical cystectomy following a bladder cancer diagnosis, higher number of comorbid conditions was associated with a lower likelihood of lymph node dissection, and a lower number of examined lymph nodes. These patients were also less likely to receive postoperative chemotherapy. Higher number of comorbid conditions also can lead to a delay in starting proper treatment. Among 24833 breast cancer patients who underwent lumpectomy, 56\% received radiation therapy. Having more comorbid conditions was associated with longer delay in the initiation of radiation therapy [68]. Hypertension, cardiac disease, and arthritis are the three most common comorbidities among older cancer patients [69]. Proper management of these comorbidities is of critical importance because it may lead to improved patient's outcome for example in a study of 233 diabetic prostate cancer patients, treatment of diabetes with thiazolidinediones and metformin was associated with improved overall survival of the patients [70].

At a minimum, cancer care providers should ascertain older cancer patients' past medical history. Whether each disease causes patients to have active symptoms should also be documented. Name and contact information of primary care provider as well as other specialists involved in patient's care should be asked from the patient and caregiver. Proper communication between cancer care provider and other healthcare providers should happen as need arises since inefficient communication between health care team members may lead to patient harm and adverse events [71].

\section{Emotional status}

Depression is a psychiatric syndrome that commonly co-occurs with cancer [72]. Significant data demonstrate the high prevalence of depressive symptoms among the patients with a wide variety of cancer types [73]. Depression prevalence increases with disease severity and symptoms such as pain and fatigue [72]. Although distress and anxiety may decrease with age, a study of 736 prostate cancer patients 
with median age of 68 showed that depressive symptoms significantly increased with age [74]. Geriatric depression scale (GDS), a self administered 30-item questionnaire is specifically designed for rating the depression among elderly [75]. Patients receive a score of 1 for each depressive/abnormal answer to the questions. A total score of $0-10$ is considered normal, while a score of $>10$ is a positive screen for depression [76]. A brief and commonly used tool to evaluate psychological distress in cancer survivors is the Hospital Anxiety and Depression Scale (HADS) [77]. This instrument consists of anxiety and depression subscales with total number of 14 questions. Every item is rated on a 4-point scale, giving a maximum score of 21 for each subscale. Scores of $\geq 11$ on either subscale are considered to be a significant for psychological morbidity, while scores of 8-10 and 0-7 represent borderline and normal, respectively [78]. PHQ-9 depression scale is a 9-item self-administered questionnaire which is widely used in clinical and research settings due to its brevity and validity in the diagnosis of depression [79]. For severity assessment, the PHQ-9 score can range from 0 to 27 since each one of the items can be scored from 0 (not at all) to 3 (nearly every day). The score divided into 5 categories of increasing severity: 0-4 (none), 5-9 (mild), 10-14 (moderate), 15-19 (moderately severe), and 20-27 (severe) [80]. Depression in the elderly has been associated with increased need of informal care giving resource requirements [81,82]. In a study by Kornblith et al. using monthly telephone calls to evaluate and decrease depression in older cancer survivors, patients who received the monthly telephone call describing cancer-related psychosocial issues and available resources had significantly less depression $(\mathrm{P}=$ $.0004)$, anxiety $(\mathrm{P}<.0001)$, and overall distress $(\mathrm{P}<.0001)$ compared to the control group $[50,83]$. Moreover, depression can be associated with outcomes in older cancer survivors. An epidemiologic study on 24,696 older breast cancer patients (67-90 years old) showed that patients with a recent diagnosis of depression were at risk for receiving less-than-optimal treatment for their cancer, and they also had worse survival [84]. In a study of older women (median age of 76) with advanced ovarian cancer undergoing platinum based chemotherapy, depression was the strongest prognostic factor correlated with severe toxicity and poor overall survival [85].

\section{Conclusion}

The existence of age-related health problems in older cancer patients is bound to have an impact on the course of their cancer treatment, prognosis and survival. Comprehensive Geriatric Assessment is an evidence-based approach to evaluate different aspects of elderly patients with cancer. A more in depth evaluation through the CGA may help in the detection of the elderly patients issues and facilitate the implementation of appropriate interventions to help them better benefit from different cancer treatment modalities.

\section{References}

1. (2014) Cancer facts and figures. American Cancer Society: Atlanta, Georgia, USA.

2. de Moor JS, Mariotto AB, Parry C, Alfano CM, Padgett L, et al. (2013) Cancer survivors in the United States: prevalence across the survivorship trajectory and implications for care. Cancer Epidemiol Biomarkers Prev 22: 561-570.

3. Berger NA, Savvides P, Koroukian SM, Kahana EF, Deimling GT, et al (2006) Cancer in the elderly. Trans Am Clin Climatol Assoc 117: 147-155.
4. (2012) National population projections: summary tables. Table 2- Projections of the population by selected age groups and sex for the United States: 2015 to 2060. United States Census Bureau.

5. Covinsky KE, Justice AC, Rosenthal GE, Palmer RM, Landefeld CS (1997) Measuring prognosis and case mix in hospitalized elders. The importance of functional status. J Gen Intern Med 12: 203-208.

6. Inouye SK, Peduzzi PN, Robison JT, Huges JS, Horwitz RI, et al. (1998) Importance of functional measures in predicting mortality among older hospitalized patients. JAMA 279: 1187-1193.

7. Lee SJ, Lindquist K, Segal MR, Covinsky KE (2006) Development and validation of a prognostic index for 4-year mortality in older adults. JAMA 295: 801-808.

8. Hendee W (1990) American medical association white paper on elderly health. Report of the council on scientific affairs. Arch Intern Med 150: 24592472.

9. Pal SK, Katheria V, Hurria A (2010) Evaluating the older patient with cancer: understanding frailty and the geriatric assessment. CA cancer J Clin 60: 120132

10. Extermann M, Aapro M, Bernabei R, Cohen HJ, Droz JP, et al. (2005) Use of comprehensive geriatric assessment in older cancer patients: recommendations from the task force on CGA of the International Society of Geriatric Oncology (SIOG). Crit Rev Oncol Hematol 55: 241-252.

11. Extermann M, Hurria A (2007) Comprehensive geriatric assessment for older patients with cancer. J Clin Oncol 25: 1824-1831.

12. Oken MM, Creech RH, Tormey DC, Horton J, Davis TE, et al. (1982) Toxicity and response criteria of the Eastern cooperative oncology group. Am J Clin Oncol 5: 649-655.

13. Schag CC, Heinrich RL, Ganz PA (1984) Karnofsky performance status revisited: reliability, validity, and guidelines. J Clin Oncol 2:187-193.

14. Wallace M, Shelkey M, Hartford Institute for Geriatric Nursing (2007) Katz index of independence in activities of daily living (ADL). Urol Nurs 27: 93-94.

15. Lawton MP, Brody EM (1969) Assessment of older people: self-maintaining and instrumental activities of daily living. Gerontologist 9: 179-186.

16. Lawton MP, Brody EM (1969) Instrumental activities of daily living scale (IADL)

17. Fillenbaum GG (1987) OARS multidimensional functional assessment questionnaire, Duke University Center for the Study of Aging and Human, Durham, North Carolina.

18. Saliba D, Elliott M, Rubenstein LZ, Solomon DH, Young RT, et al. (2001) The vulnerable elders survey: a tool for identifying vulnerable older people in the community. J Am Geriatr Soc 49: 1691-1699.

19. Hurria A, Togawa K, Mohile SG, Owusu C, Klepin HD, et al. (2011) Predicting chemotherapy toxicity in older adults with cancer: a prospective multicenter study. J Clin Oncol 29: 3457-3465

20. Extermann M, Boler I, Reich RR, Lyman GH, Brown RH, et al. (2012) Predicting the risk of chemotherapy toxicity in older patients: The chemotherapy risk assessment scale for high-age patients (CRASH) score. Cancer 118: 3377 3386.

21. Repetto L, Frantino L, Audisio RA, Venturino A, Gianni W, et al. (2002) Comprehensive geriatric assessment adds information to Eastern cooperative oncology group performance status in elderly cancer patients: an Italian group for geriatric oncology study. J Clin Oncol 20: 494-502.

22. Korc-Grodzicki B, Downey RJ, Shahrokni A, Kingham TP, Patel SG, et al. (2014) Surgical considerations in older adults with cancer. J Clin Oncol 32: 2647-2653.

23. Kristjansson SR, Jordhoy MS, Nesbakken A, Skovlund E, Bakka A, et al. (2010) Which elements of a comprehensive geriatric assessment (CGA) predict post-operative complications and early mortality after colorectal cancer surgery? J Geriatr Oncol 1: 57-65. 
24. Parks RM, Hall L, Tang W, Howard P, Lakshamanan R, et al. (2015) The potential value of comprehensive geriatric assessment in evaluating olde women with primary operable breast cancer undergoing surgery or nonoperative treatment-- a pilot study. J Geriatr Oncol 6: 46-51.

25. PACE participants, Audisio RA, Pope D, Ramesh HS, Gennari R, et al. (2008) Shall we operate? Preoperative assessment in elderly cancer patients (PACE) can help. A SIOG surgical task force prospective study. Crit Rev Oncol Hematol 65: 156-163.

26. Cesari M, Landi F, Torre S, Onder G, Lattanzio F, et al. (2002) Prevalence and risk factors for falls in an older community-dwelling population. J Geronto A Biol Sci Med Sci 57: M722-M726.

27. Rubenstein LZ (2006) Falls in older people: epidemiology, risk factors and strategies for prevention. Age Ageing 35 Suppl 2: ii37-ii41.

28. Gewandter JS, Fan L, Magnuson A, Mustian K, Peppone L, et al. (2013) Falls and functional impairments in cancer survivors with chemotherapy-induced peripheral neuropathy (CIPN): a University of Rochester CCOP study. Support Care Cancer 21: 2059-2066.

29. Ward PR, Wong MD, Moore R, Naeim A (2014) Fall-related injuries in elderly cancer patients treated with neurotoxic chemotherapy: a retrospective cohort study. J Geriatr Oncol 5: 57-64.

30. Hurria A, Togawa K, Mohile SG, Owusu C, Klepin HD, et al. (2010) Predicting chemotherapy toxicity in older adults with cancer: A prospective 500 patient multicenter study. J Clin Oncol 28 Suppl 15: 9001.

31. Tan CS, Read JA, Phan VH, Beale PJ, Peat JK, et al. (2015) The relationship between nutritional status, inflammatory markers and survival in patients with advanced cancer: a prospective cohort study. Support Care Cancer 23: 385 391

32. Bozzetti F, Gianotti L, Braga M, Di Carlo V, Mariani L (2007) Postoperative complications in gastrointestinal cancer patients: the joint role of the nutritional status and the nutritional support. Clin Nutr 26: 698-709.

33. Guigoz Y, Vellas B, Garry PJ (1997) Mini nutritional assessment: a practica assessment tool for grading the nutritional state of elderly patients. In: Vellas BJ, Guigoz Y, Garry PJ, Albarede JL (eds). The mini nutritional assessment: MNA. Nutrition in the elderly. pp.15-60.

34. Unsal D, Mentes B, Akmansu M, Uner A, Oguz M, et al. (2006) Evaluation of nutritional status in cancer patients receiving radiotherapy: a prospective study. Am J Clin Oncol 29: 183-188.

35. De Luis D, Izaola O, Terroba MC, Cuellar L, Ventosa M, et al. (2015) Effect of three different doses of arginine enhanced enteral nutrition on nutritional status and outcomes in well nourished postsurgical cancer patients: a randomized single blinded prospective trial. Eur Rev Med Pharmacol Sci 19: 950-955.

36. Riccardi D, Allen K (1999) Nutritional management of patients with esophageal and esophagogastric junction cancer. Cancer Control 6: 64-72.

37. Di Fiore F, Lecleire S, Pop D, Rigal O, Hamidou H, et al. (2007) Baseline nutritional status is predictive of response to treatment and survival in patients treated by definitive chemoradiotherapy for a locally advanced esophageal cancer. Am J Gastroenterol 102: 2557-2563.

38. Robinson TN, Raeburn CD, Tran ZV, Angles EM, Brenner LA, et al. (2009) Postoperative delirium in the elderly: risk factors and outcomes. Ann Surg 249: $173-178$.

39. Wells JL, Seabrook JA, Stolee P, Borrie MJ, Knoefel F (2003) State of the ar in geriatric rehabilitation. Part I: review of frailty and comprehensive geriatric assessment. Arch Phys Med Rehabil 84: 890-897.

40. Kurlowicz L, Wallace M (1999) The mini-mental state examination (MMSE). J Gerontol Nurs 25: 8-9.

41. Nasreddine ZS, Phillips NA, Bedirian V, Charbonneau S, Whitehead V, et al. (2005) The montreal cognitive assessment, MoCA: a brief screening tool for mild cognitive impairment. J Am Geriatr Soc 53: 695-699.

42. Borson S, Scanlan JM, Watanable J, Tu SP, Lessig M, et al. (2005) Simplifying detection of cognitive impairment: comparison of the mini-cog and mini-mental state examination in a multiethnic sample. J Am Geriatr Soc 53
871-874

43. Callahan CM, Hendrie HC, Tierney WM (1995) Documentation and evaluation of cognitive impairment in elderly primary care patients. Ann Intern Med 122 : $422-429$

44. Tannock IF, Ahles TA, Ganz PA, Van Dam FS (2004) Cognitive impairment associated with chemotherapy for cancer: report of a workshop. J Clin Oncol 22: 2233-2239.

45. van Dam FS, Schagen SB, Muller MJ, Boogered W, vd Wall E, et al. (1998) Impairment of cognitive function in women receiving adjuvant treatment for high-risk breast cancer: high-dose versus standard-dose chemotherapy. J Natl Cancer Inst 90: 210-218

46. Nelson CJ, Lee JS, Gamboa MC, Roth AJ (2008) Cognitive effects of hormone therapy in men with prostate cancer: a review. Cancer 113: 10971106.

47. Jamadar RJ, Winters MJ, Maki PM (2012) Cognitive changes associated with ADT: a review of the literature. Asian J Androl 14: 232-238.

48. Reinhard SC, Given RB, Petlick NH, Bemis A (2008) Supporting family caregivers in providing care. In: Hughes RG (ed). Patient safety and quality: An evidence-based handbook for nurses. Rockville: Agency for Healthcare Research and Quality (US)

49. Chan YK, Lee RL (2006) Network size, social support and happiness in later life: A comparative study of Beijing and Hong Kong. J Happiness Stud 7: 87112.

50. Seeman TE, Lusingnolo TM, Albert M, Berkman L (2001) Social relationships, social support, and patterns of cognitive aging in healthy, high-functioning older adults: MacArthur studies of successful aging. Health Psychol 20: 243255.

51. Kroenke $\mathrm{CH}$, Kubzansky LD, Schernhammer ES, Holmes MD, Kawachi I (2006) Social networks, social support, and survival after breast cancer diagnosis. J Clin Oncol 24: 1105-1111.

52. Wilcox S, Evenson KR, Aragaki A, Wassertheil-Smoller S, Mouton CP, et al. (2003) The effects of widowhood on physical and mental health, health behaviors, and health outcomes: The Women's Health Initiative. Health Psychol 22: 513-522

53. RAND Health (2015) Medical outcome study: Social support survey instrument.

54. Zimet GD, Dahlem NW, Zimet SG, Farley GK (1988) The multidimensiona scale of perceived social support. J Pers Assess 52: 30-41.

55. Maggiore RJ, Gross CP, Hurria A (2010) Polypharmacy in older adults with cancer. Oncologist 15: 507-522.

56. Gnjidic D, Hilmer SN, Blyth FM, Naganathan V, Waite L, et al. (2012) Polypharmacy cutoff and outcomes: five or more medicines were used to identify community-dwelling older men at risk of different adverse outcomes. J Clin Epidemiol 65: 989-995

57. Jyrkka J, Enlund H, Korhonen MJ, Sulkava R, Hartikainen S (2009) Polypharmacy status as an indicator of mortality in an elderly population. Drugs Aging 26: 1039-1048.

58. Campanelli CM (2012) American geriatrics society updated beers criteria for potentially inappropriate medication use in older adults: The American geriatrics society 2012 beers criteria update expert panel. J Am Geriatr Soc 60: 616-631.

59. Balducci L, Goetz-Parten D, Steinman MA (2013) Polypharmacy and the management of the older cancer patient. Ann Oncol 24 Suppl 7: vii36-vii40.

60. Riechelmann RP, Moreira F, Smaletz O, Saad ED (2005) Potential for drug interactions in hospitalized cancer patients. Cancer Chemother Pharmacol 56: $286-290$

61. Riechelmann RP, Zimmermann C, Chin SN, Wang L, O'Carroll A, et al. (2008) Potential drug interactions in cancer patients receiving supportive care exclusively. J Pain Symptom Manage 35: 535-543. 
62. Maggiore RJ, Dale W, Gross GP, Feng T, Tew WP, et al. (2014) Polypharmacy and potentially inappropriate medication use in older adults with cance undergoing chemotherapy: effect on chemotherapy-related toxicity and hospitalization during treatment. J Am Geriatr Soc 62: 1505-1512.

63. Koroukian SM, Murray P, Madigan E (2006) Comorbidity, disability, and geriatric syndromes in elderly cancer patients receiving home health care. $J$ Clin Oncol 24: 2304-2310.

64. Starfield B, Lemke KW, Herbert R, Pavlovich WD, Anderson G (2005) Comorbidity and the use of primary care and specialist care in the elderly. Ann Fam Med 3: 215-222.

65. Charlson ME, Charlson RE, Peterson JC, Marinopolos, Briggs WM, et al (2008) The Charlson comorbidity index is adapted to predict costs of chronic disease in primary care patients. J Clin Epidemiol 61: 1234-1240.

66. Shahir MA, Lemmens VE, van de Poll-Franse LV, Voogd AC, Martijn H, e al. (2006) Elderly patients with rectal cancer have a higher risk of treatmentrelated complications and a poorer prognosis than younger patients: a population-based study. Eur J Cancer 42: 3015-3021.

67. Koppie TM, Serio TM, Vickers AJ, Vora K, Dalbagni G, et al. (2008) Ageadjusted charlson comorbidity score is associated with treatment decisions and clinical outcomes for patients undergoing radical cystectomy for bladde cancer. Cancer 112: 2384-2392.

68. Hershman DL, Wang X, Mcbride R, Jacabson JS, Grann VR, et al. (2006) Delay in initiating adjuvant radiotherapy following breast conservation surgery and its impact on survival. Int J Radiat Oncol Biol Phys 65: 1353-1ss360.

69. Yancik R, Havlik RJ, Wesley MN, Ries L, Long S, et al. (1996) Cancer and comorbidity in older patients: a descriptive profile. Ann Epidemiol 6: 399-412.

70. He XX, Tu SM, Lee MH, Yeung SC (2011) Thiazolidinediones and metformin associated with improved survival of diabetic prostate cancer patients. Ann Oncol 22: 2640-2645

71. Dingley C, Daugherty K, Derieg MK, Persing R (2008) Improving patien safety through provider communication strategy enhancements. In: Henriksen K, Battles JB, Keyes MA, et al., (eds). Advances in patient safety: New directions and alternative approaches (Vol. 3: Performance and Tools) Rockville (MD): Agency for Healthcare Research and Quality (US).

72. Spiegel D, Giese-Davis J (2003) Depression and cancer: mechanisms and disease progression. Biol Psychiatry 54: 269-282.

73. Massie MJ (2004) Prevalence of depression in patients with cancer. J Nat
Cancer Inst Monogr 32: 57-71.

74. Nelson CJ, Weinberger MI, Balk E, Holland J, Breitbart W, et al. (2009) The chronology of distress, anxiety, and depression in older prostate cancer patients. Oncologist 14: 891-899.

75. Yesavage JA, Brink TL, Rose TL, Lum O, Huang V, et al. (1982) Development and validation of a geriatric depression screening scale: a preliminary report. J Psychiatr Res 17: 37-49.

76. Ebell MH (2013) Geriatric depression scale. In: Evidence-based diagnosis: A handbook of clinical prediction rules, Springer Science \& Business Media.

77. Herrmann C (1997) International experiences with the hospital anxiety and depression scale--a review of validation data and clinical results. J Psychosom Res 42: 17-41.

78. Zigmond AS, Snaith RP (1983) The hospital anxiety and depression scale. Acta Psychiatr Scand 67: 361-370.

79. Kroenke K, Spitzer RL, Williams JB (2001) The PHQ-9: validity of a brief depression severity measure. J Gen Intern Med 16: 606-613.

80. Kroenke K, Spitzer RL (2002) The PHQ-9: a new depression diagnostic and severity measure. Psychiatr Ann 32: 1-7.

81. Penninx BW, Guralnik JM, Ferrucci L, Simonsick EM, Deeg DJ, et al. (1998) Depressive symptoms and physical decline in community-dwelling older persons. JAMA 279: 1720-1726.

82. Langa KM, Valenstein MA, Fensrick AM, Kabeto MU, Vijan S (2004) Extent and cost of informal caregiving for older Americans with symptoms of depression. Am J Psychiatry 161: 857-863.

83. Kornblith AB, Dowell JM, Herndon JE 2nd, Engelman BJ, Bauer-Wu S, et al. (2006) Telephone monitoring of distress in patients aged 65 years or older with advanced stage cancer: a cancer and leukemia group B study. Cancer 107: 2706-2714.

84. Goodwin JS, Zhang DD, Ostir GV (2004) Effect of depression on diagnosis, treatment, and survival of older women with breast cancer. J Am Geriatr Soc 52: 106- 111

85. Freyer G, Geay JF, Touzet S, Provencal J, Weber B, et al. (2005) Comprehensive geriatric assessment predicts tolerance to chemotherapy and survival in elderly patients with advanced ovarian carcinoma: a GINECO study. Ann Oncol 16: 1795-1800. 